\title{
Finite element analysis (FEA) modelling and experimental verification to optimise flexible electronic packaging for e-textiles
}

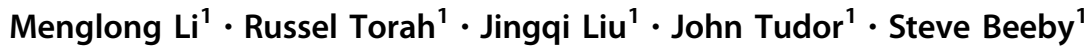

Received: 13 August 2018 / Accepted: 11 March 2020/Published online: 14 March 2020

(C) The Author(s) 2020

\begin{abstract}
In this paper a three-dimensional model of a novel electronic package has been developed using Finite element analysis to evaluate the shear load, tensile, bending and thermal stresses. Simulations of a complete flexible flip chip electronic packaging method are performed to minimize stresses on the packaged electronic device to improve robustness and reliability. Three component under-fill adhesives (Loctite 4860, Loctite 480 and Loctite 4902) and three circuit substrate materials (Kapton, Mylar and PEEK) are compared and the optimal thickness of each is found by shear load, tensile load, bending test and thermal expansion simulations. A fixed die size of $3.5 \mathrm{~mm} \times 8 \mathrm{~mm} \times 0.53 \mathrm{~mm}$ has been simulated and evaluated experimentally under shear and bending load. The shear and bending experimental results show good agreement with the simulation results and verify the simulated optimal thickness of the adhesive layer. The Kapton substrate together with the Loctite 4902 adhesive were identified as the optimum in the simulation. The simulation of under-fill adhesive and substrate thickness identified an optimum configuration of a $0.045-0.052 \mathrm{~mm}$ thick substrate layer and a $0.042-0.045 \mathrm{~mm}$ thickness of the Loctite 4902 adhesive. The bending simulation has also been used to determine the neutral axis of the encapsulated electronic package in this paper, thus identifying the optimal material and thickness for the encapsulation layer of the package.
\end{abstract}

\section{Introduction}

In today's society, microelectronics technology plays a significant role in people's lives as is evidenced by the abundance of devices such as mobile phones and laptops. Electronic textile technology seeks to further integrate microelectronics technology by combining electronics with textiles to provide convenient and comfortable access (Bonderover and Wagner 2004). An electronic textile (etextile) is a textile with integrated electronic functionality. E-textiles can be applied in many areas such as in clothing, for medical application or in home furnishings (Li 2017a; Meoli and May-Plumlee 2002). We aim to produce electronic textiles by directly mounting electronic components, in die form, within the yarn of the textile on a miniature flexible substrate. However, E-textiles are often a wearable product and, as such, are subject to human motion activities making integrated electronic components vulnerable to

Menglong Li

ml1g12@soton.ac.uk

1 Department of Electronic and Computer Science, University of Southampton, Southampton, UK different kinds of stresses such as shear and bending which can cause embedded electronic devices to fail or malfunction. Consequently, the functionality which can be integrated in the textile by means of electronic components is limited by the packaging methods used to protect and mount the components within the textile.

Reliability and flexibility are two key factors for functional e-textiles (Katragadda and $\mathrm{Xu} 2008$ ) and the electronic chip packaging processes described in this present paper aims to maximize the reliability of the packaged electronic chip whilst, at same time, keeping the package as thin as possible to increase the flexibility of the overall assembly. Different types of substrates, under-fill/adhesive, chip and encapsulation materials have been used to package electronics into the textile. Little has been mentioned of how to improve the reliability of the electronic package by analysing the stress distribution within the electronic package (Paul et al. 2014; Rajoo 2010). The flexible electronic packaging method analysed in this paper is a die pod, which is a three layer assembly consisting of an electronic die, the adhesive layer and the plastic layer as shown in Fig. 1. Flip-chip technology is used to mount ultra-thin die onto thin flexible polymer film strips. 


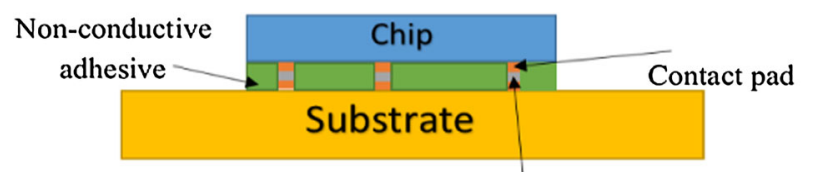

Electrically Conductive adhesive

Fig. 1 Schematic cross section though a die pod showing example of flip-chip configuration of electronic die on plastic package

Electrical interconnections between the electronic die and the bottom plastic layer can be made using conductive adhesive or solder (Kallmayer 2003; Castano and Flatau 2014). Non-conductive adhesive is applied into the empty space between die and substrate to act as an under-fill. Under-fill is used in electronic die packaging to (a) reduce thermal stresses caused by the difference of the coefficient of thermal expansion between the silicon die and the substrate and, (b) increase the reliability of electronic packaging interconnections when mechanical impact and shock occurs (Chan et al. 2004; Nysaether et al. 2000; Loh et al. 2013; Wan et al. 2007; Li 2017b). This package is used for all simulation and experimental investigations in this paper to determine the optimal thickness and materials of the top and bottom plastic and adhesive layers.

\section{Material and modelling methods}

Achieving a reliable methodology for packaging bare die on the thin plastic substrates requires an extensive modelling exercise to minimize stresses in the assembly that occur due to bending and temperature changes during normal operation. The packaging stresses have been modelled using finite element analysis (FEA) to perform static stress analysis. The software package used is ANSYS and a key design consideration is the size of the package, which should be minimized where possible.

The FEA has been used to determine the stresses in the mounted adhesive/plastic substrate layer under four conditions. The four conditions include a shear load, a tensile load, a three point bending load and a temperature load. These analyses have been used to optimize the thickness of the adhesive and substrate layers used in the assembly to minimize the stresses. The stress analysis has also been used to evaluate three under-fill adhesives (Loctite 4860, Loctite 480 and Loctite 4902) and three plastic substrates (Kapton, Mylar and PEEK) materials. From maximum shear stress theory and maximum distortion energy theory, the maximum shear stress and von-Mises stress can be determined in order to evaluate the failure of ductile materials, and from Maximum normal stress theory, the compression and tensile stresses are used to evaluate the failure of brittle materials (USA, D.o.D.a. 1996). Therefore the maximum shear stress and von-Mises stress in the adhesive and substrate layer, and compression and tensile stress in die layer have been analysed in this paper. Table 1 shows the material properties for three under-fill adhesives and three plastic substrates.

The shear load modelling method is shown in Fig. 2a, in this figure, the boundary condition for shear load FEA modelling are: a force is applied on the left edge of die and perpendicular to the primary substrate, the left and right edges of substrate are fixed. The top layer of the electronic package is the die, the middle layer is the adhesive and the bottom layer is the substrate. Figure $2 b$ shows the three point bending load modelling method, Points $\mathrm{a}, \mathrm{b}$ and $\mathrm{c}$ are assumed as the three points in model. The boundary condition for three point bending load FEA modelling are: point $\mathrm{a}$ and $\mathrm{b}$ are fixed in the bending test while point $\mathrm{c}$ is where the force is applied in the negative $\mathrm{Z}$ direction. In both shear and bending simulations reliability is determined by observing the stresses in the different layers. The element size in the FEA simulation was defined by specifying the number of elements along key dimensions of the model. The long edge ( $X$ direction in Fig. 2a) and short edge of the die and adhesive were divided into 8 and 4 elements respectively. The thickness of the die ( $\mathrm{Z}$ direction) was divided into 3 elements whilst the adhesive has 2 elements through its thickness. The substrate has 20 elements along its length and 5 elements across its width and through its thickness. The ANSYS Multizone mesh setting was used to perform the mesh operation. To accommodate the different mesh sizes, two contacts were defined between the substrate and the adhesive and also between the adhesive and the die.

Figure 3a shows the tensile load modelling method, the boundary condition for tensile load FEA modelling are: a force applied on the top surface of die, the left and right edges of substrate are fixed and the top surface of substrate will be fixed in any directions. The thermal expansion modelling method is shown in Fig. 3b, the boundary condition for thermal expansion FEA modelling are: the left edge of substrate is fixed, and the whole package is heated up from 0 to $80{ }^{\circ} \mathrm{C}$.

To prove the simulation results, shear load experiments have been undertaken in conjunction with shear load simulations. An electronic package holder and an Electropuls 1000 mechanical test machine, shown in Fig. 4, are required for the shear load experiment. Figure $4 \mathrm{a}$ is an sample holder for the shear load experiments: platforms "a" and " $\mathrm{b}$ " are the platforms for applying force to the package, "c" is the electronic package sample which is held in position by two holders, " $e$ " which is used to fix the left edge of the sample, and the other holder is behind the beam used to fix the right edge of sample, "d" is an edge of load beam used to apply force onto one edge of the 
Table 1 The properties of materials used in this paper (Henkel 2019; Boedeker Plastics, Ins. 2019; DUPONT ${ }^{\mathrm{TM}}$ KAPTON $^{\circledR} \mathrm{HN}$ polyimide 2019; Mylay 2019)

\begin{tabular}{lclll}
\hline Product & Young's modules $(\mathrm{MPa})$ & $\mathrm{CTE}\left(\mathrm{K}^{-1}\right)$ & Density $\left(\mathrm{g} \mathrm{cm}^{-3}\right)$ & Tensile strength $(\mathrm{MPa})$ \\
\hline Loctite 4860 & 430 & 0.0001 & 1.07 & $\geq 5$ \\
Loctite 435 & 2000 & 0.00008 & 1.1 & $\geq 1.8$ \\
Loctite 4902 & 400 & 0.000425 & 1.06 & 16 \\
PEEK & 3800 & $4.7 \mathrm{E}-05$ & 1.32 & 98 \\
Kapton & 2500 & $2 \mathrm{E}-05$ & 1.42 & 231 \\
Mylar & 3100 & $1.7 \mathrm{E}-05$ & 1.39 & 138 \\
Silicon die & 15,000 & $1.1 \mathrm{E}-0.6$ & 2.33 & 7000 \\
\hline
\end{tabular}

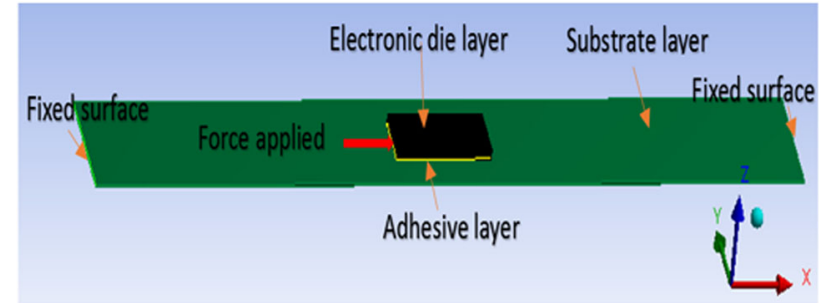

(a)

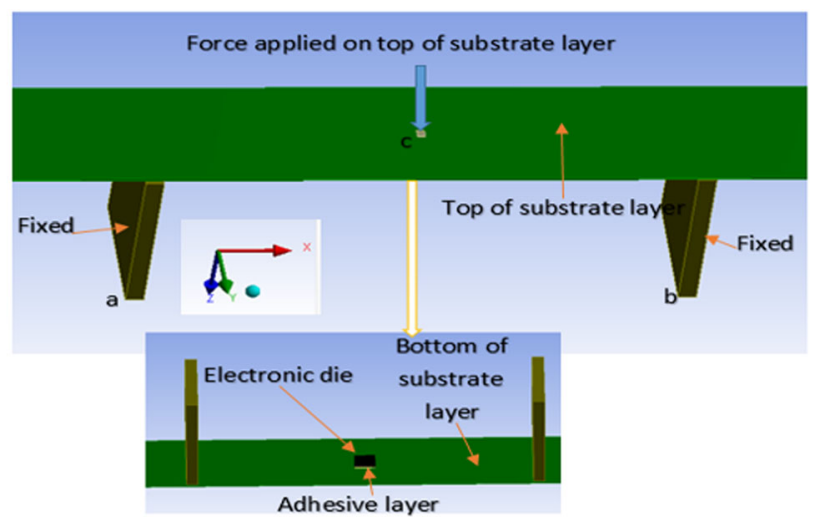

(b)

Fig. 2 FEA modelling methods, a shear load model and $\mathbf{b}$ three point bending load model

packaged die. Figure $4 \mathrm{~b}$ shows an Electroplus 1000 mechanical test machine designed for dynamic and static testing of a wide range of materials and components. In the shear load test, the Electroplus was used to apply an external force to the platform in positions "a" and " $b$ " of the holder. To validate the simulation results, the boundary conditions for the shear load simulations were replicated for the shear load experiment. The procedures for the shear load experiments are closely correlated to the shear load simulations in that: (1) the Electroplus machine is used to apply an external force to one edge surface of the die; (2) the two edges of substrate are fixed by the two holders.

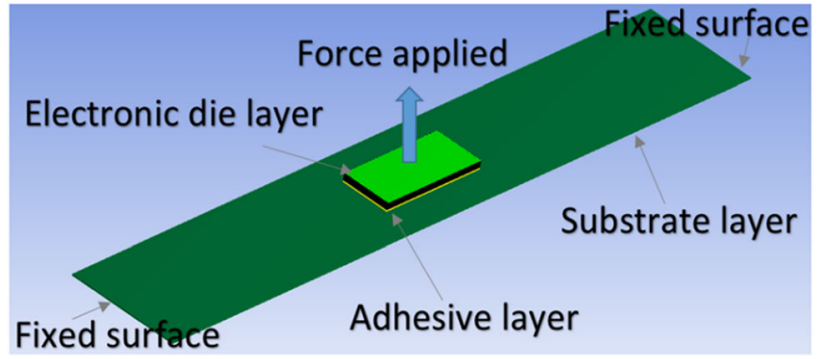

(a)

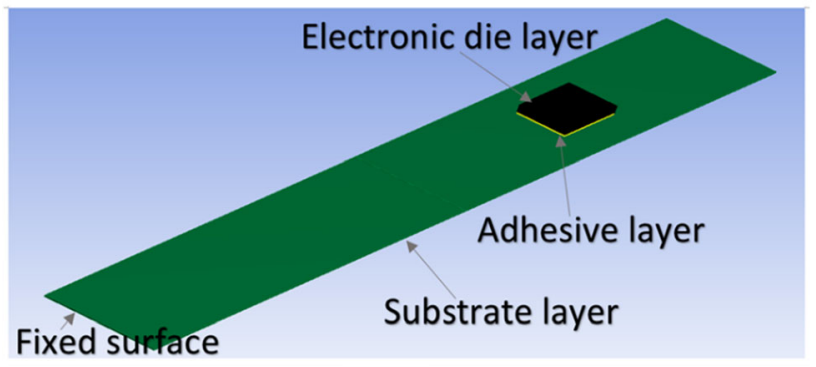

(b)

Fig. 3 FEA modelling methods, a tensile load model and $\mathbf{b}$ thermal expansion model

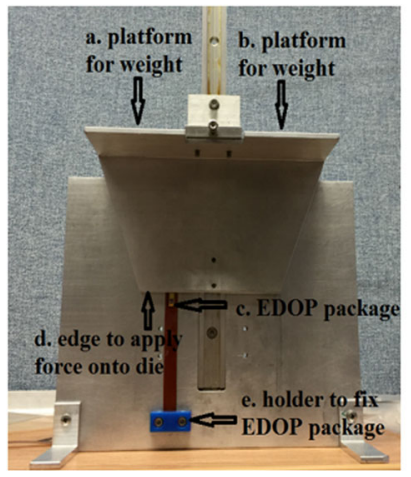

(a)

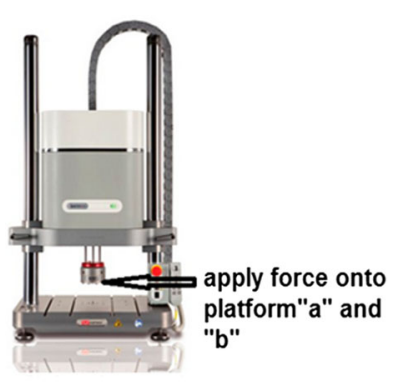

(b)
Fig. 4 Equipment for shear load experiments, a electronic package sample holder for shear load test and b Electroplus 1000 mechanical test machine used to apply force 


\section{Modelling results and experiment verification of modelling}

The FEA modelling results show the effect of substrate and adhesive thickness for stresses inside electronic package. The effect of the choice of adhesive and substrate materials on the electronic packaging have also been discussed under the four modelling methods.

The maximum shear and von-Mises stresses have been simulated from each model. The maximum shear stress and von-Mises stress are obtained in adhesive and substrate layer. The width and length of silicon die, adhesive layer and Kapton substrate are fixed at $3.5 \mathrm{~mm} \times 8 \mathrm{~mm}$, $3.5 \mathrm{~mm} \times 8 \mathrm{~mm}$ and $10 \mathrm{~mm} \times 180 \mathrm{~mm}$ respectively and the thickness of die is fixed at $0.53 \mathrm{~mm}$. In this work the aim is to keep the package as thin as possible to increase the flexibility of the overall assembly, so adhesive in thickness ranges of $0.005-0.07 \mathrm{~mm}$ have been tested in simulation and experiment, and the thickness of substrate between 0.01 and $0.08 \mathrm{~mm}$ also have been simulated in this paper to identify the optimum thickness of adhesive and substrate layer.

\subsection{Comparision of under-fill adhesive and substrate material}

The three adhesive materials (Loctite 4860, Loctite 435 and Loctite 4902) and three substrate materials (PEEK, Kapton and Mylar) have been compared in this section. The thickness of the die, substrate and adhesive are all fixed in each test modelling method. The substrate material is Kapton when comparing the adhesive material and the Loctite 4902 is selected as adhesive material when compare substrate material. The die material is silicon. The thicknesses of the die, adhesive and substrate are fixed at $0.53 \mathrm{~mm}, 0.05 \mathrm{~mm}$ and $0.125 \mathrm{~mm}$ respectively. A loaded force of $10 \mathrm{~N}$ was used for the tensile load, three points bending load and the shear load modelling.

In an electronic package, the connections between the electronic die and the substrate (adhesive layer) are the most significant influence on the strength of the electronic package. The maximum shear stress and von-Mises stress in the adhesive layer are simulated to compare different adhesive materials under shear load and bending as shown Fig. 5. The Loctite 4902 adhesive simulated the smallest von-Mises and shear stresses when applied a $10 \mathrm{~N}$ external force, Fig. $5 \mathrm{c}$ shows that compressive and tensile stresses in the die layer do not change significantly, and the simulated compressive and tensile stresses are much less than the strength of silicon die (7000 MPa). The Loctite 4902 shows the best stress performance in shear and bending load simulations. Figure 6 shows the simulation results to

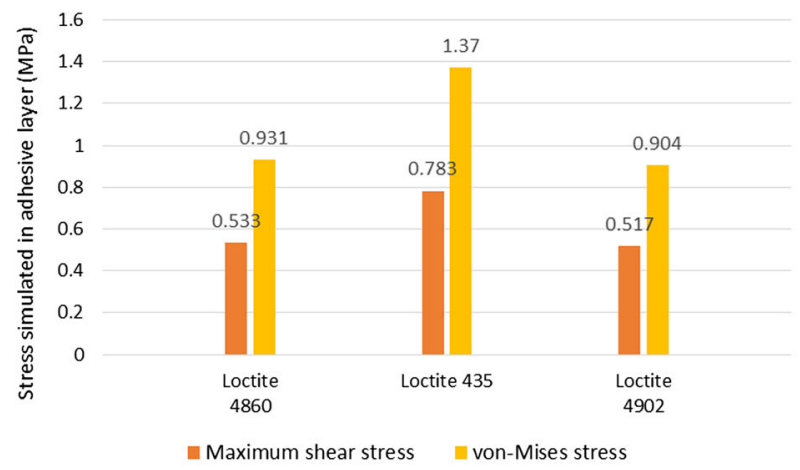

(a)

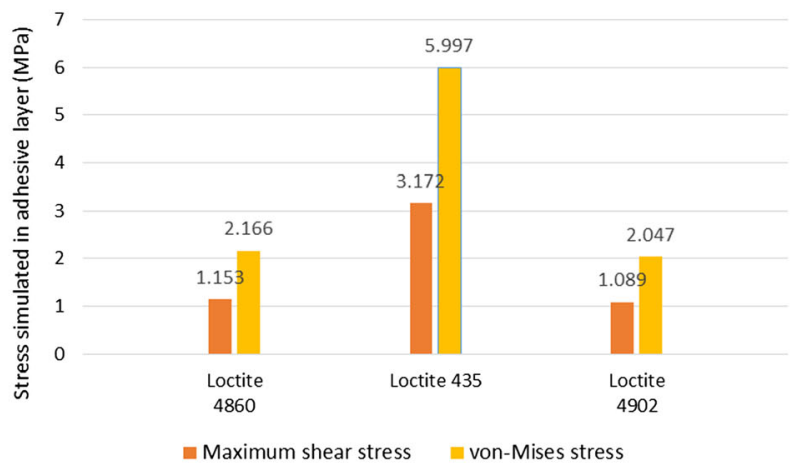

(b)

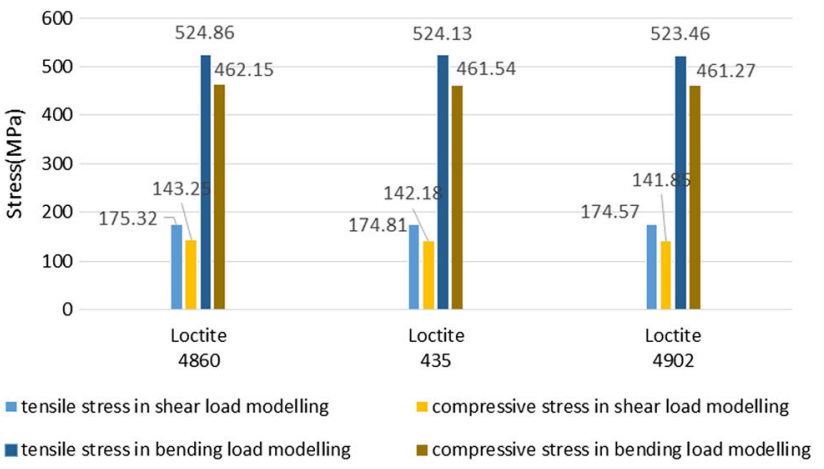

(c)

Fig. 5 Stresses simulation to compare different under-fill material, Kapton used as substrate material, a shear load modelling to simulated maximum shear stress and von-Mises stress, b bending load modelling to simulated maximum shear stress and von-Mises stress, $\mathbf{c}$ tensile and compressive stresses in die layer simulated in shear and bending load

compare adhesive materials in tensile load and thermal expansion modelling. In the tensile and thermal expansion model, the Loctite 4902 produced the smallest von-Mises and shear stresses in the adhesive layer, since it has the smallest coefficient of thermal expansion (CTE) compared with other under-fill materials. Tensile stress and compressive stress in the die have also been evaluated under a tensile load and thermal load for each of the different adhesive materials and the simulated stresses in die do not 


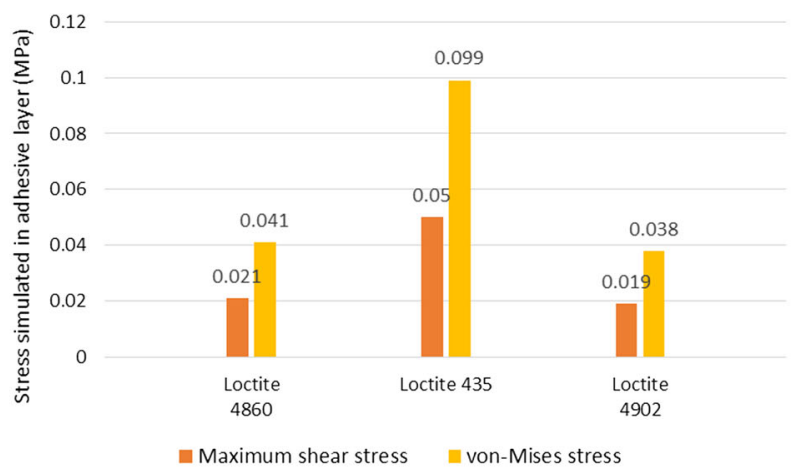

(a)

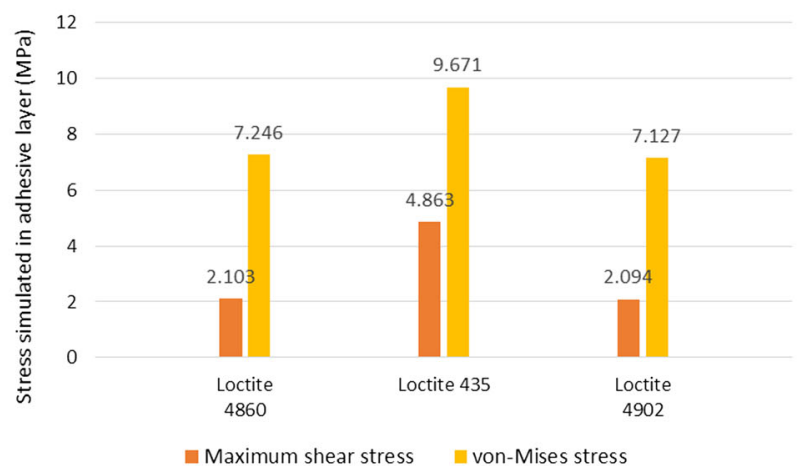

(b)

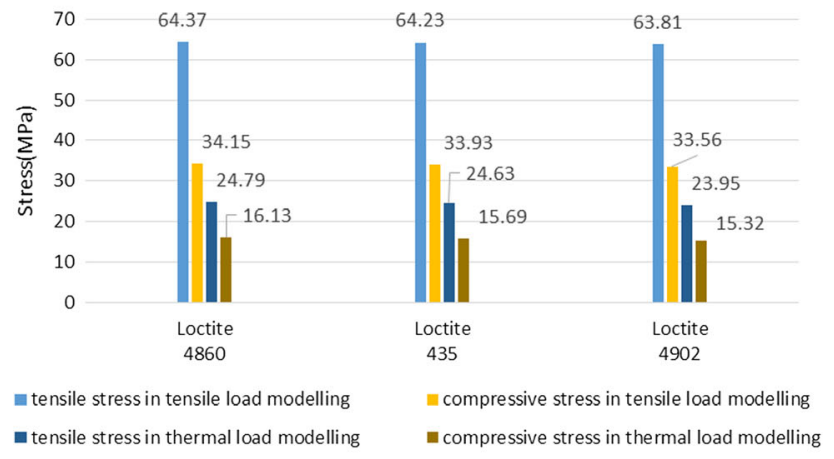

(c)

Fig. 6 Stresses simulation to compare different under-fill material, Kapton used as substrate material, a tensile load modelling to simulated maximum shear stress and von-Mises stress, b thermal expansion modelling to simulated maximum shear stress and vonMises stress, $\mathbf{c}$ tensile and compressive stresses in die layer simulated in tensile and thermal load

change significantly. All four models indicate that, of the three different adhesives, Loctite 4902 shows the best stress performance.

The maximum shear and von-Mises stress in the adhesive and substrate layer have been compared to identify the optimum substrate material. Figure 7 a shows the shear load modelling results of the maximum shear and von-Mises stress in the adhesive layer, stresses produced by Kapton substrate are almost the same as stresses produced by

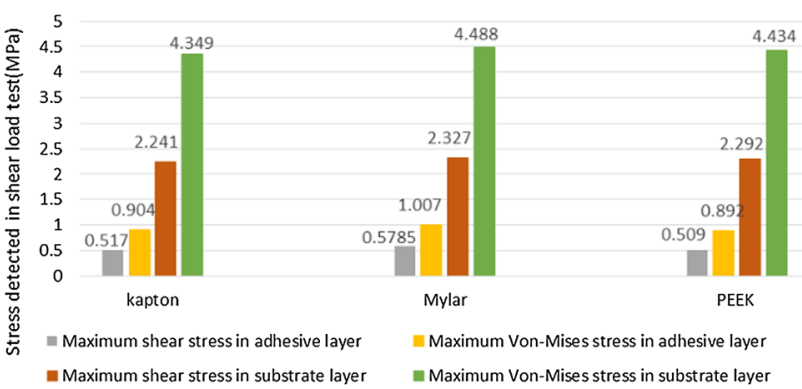

(a)

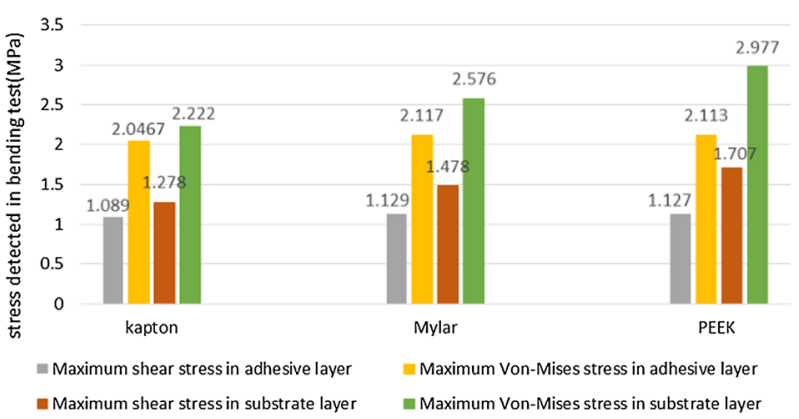

(b)

Fig. 7 Stresses simulation to compare different substrate material, Loctite 4902 used as under-fill, a shear load modelling to simulated maximum shear stress and von-Mises stress in adhesive and substrate layer, b bending test modelling to simulated maximum shear stress and von-Mises stress in adhesive and substrate layer

PEEK substrate and both are smaller than the Mylar substrate. But the Kapton substrate shows the best performance for the stresses in the substrate layer. In bending (as shown Fig. 7b), Kapton shows the smallest stresses in the adhesive layer and the substrate.

The tensile load modelling results are shown in Fig. 8a, the shear and von-Mise stresses produced by three substrate material in substrate layer are nearly zero, and the shear and von-Mise stresses in adhesive layer are very similar. Figure $8 \mathrm{~b}$ shows the thermal expansion modelling to simulated maximum shear stress and von-Mises stress in adhesive and substrate layer. The Kapton substrate shows the smallest stresses simulated in adhesive and substrate layer, so the Kapton plastic substrate shows the best stresses performance.

\subsection{Optimum thickness of adhesive and substrate layer}

The relationship between stresses inside the electronic package and the adhesive layer thickness have been studied and the optimal thickness of adhesive layer is determined in this section. Loctite 4902 adhesive and a Kapton substrate were previously determined as the best adhesive material and substrate material respectively, so the Loctite 4902 adhesive and Kapton substrate are selected in this 


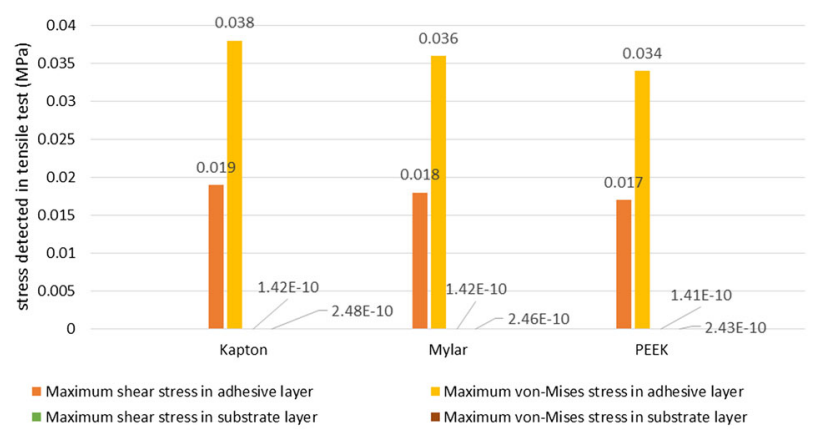

(a)

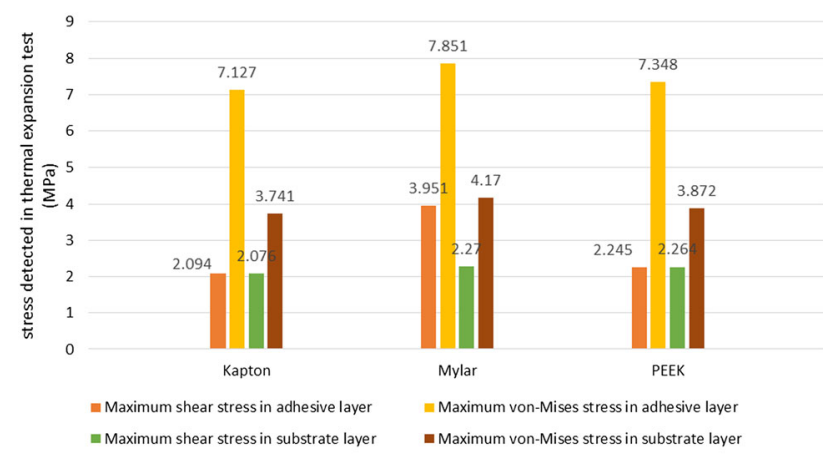

(b)

Fig. 8 Stresses simulation to compare different substrate material, Loctite 4902 used as under-fill, a tensile load modelling to simulated maximum shear stress and von-Mises stress in adhesive and substrate layer, b thermal expansion modelling to simulated maximum shear stress and von-Mises stress in adhesive and substrate layer

section. The thickness of the Kapton is fixed at $0.125 \mathrm{~mm}$. The adhesive thickness in the range of $0.005-0.07 \mathrm{~mm}$ have been examined in two test models, shown in Fig. 9, and the external force applied to all models is $20 \mathrm{~N}$. The thickness range is chosen to minimize as far as possible the electronic package size whilst providing sufficient strength.

Figure 9a shows that, when adhesive thickness is less than $0.042 \mathrm{~mm}$, as the adhesive thickness increases the shear and von-Mises stresses decrease. When the thickness of the adhesive is more than $0.045 \mathrm{~mm}$, as the adhesive thickness increases, the shear and von-Mises stresses increase. In between, in an adhesive thickness of $0.042-0.045 \mathrm{~mm}$, the minimum stress performance occurs. The maximum shear stress and von-Mises stress in bending (Fig. 9b) shows almost same stress trend, as a function of adhesive thickness, as for a shear load. The optimal Loctite 4902 adhesive thickness for the electronic package is determined by shear load and bending modelling to be between 0.042 and $0.045 \mathrm{~mm}$.

The simulations results as shown in Fig. 10 also evaluate how the substrate thickness affects the stresses in the electronic package. The configuration of a $0.042 \mathrm{~mm}$ thickness of Loctite 4902 adhesive and a Kapton substrate have been selected for modelling with the thickness of

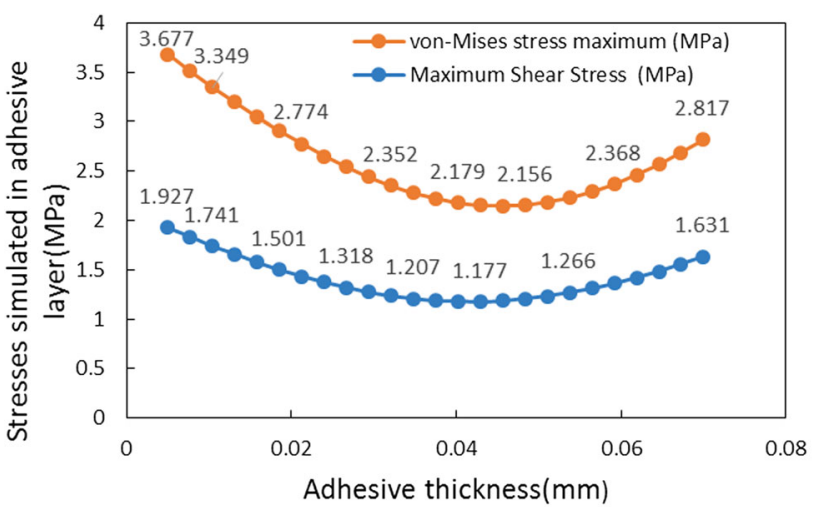

(a)

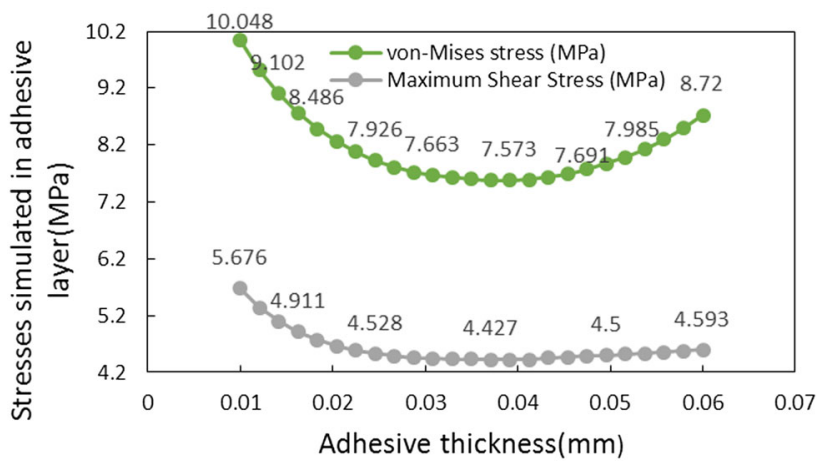

(b)

Fig. 9 Stresses simulation to determine optimal thickness of adhesive layer, a shear load modelling to simulated maximum shear stress versus adhesive thickness and von-Mises stress versus adhesive thickness, b bending test modelling to simulated maximum shear stress versus adhesive thickness and von-Mises stress versus adhesive thickness

Kapton chosen between 0.01 and $0.08 \mathrm{~mm}$. The external stress applied in shear and bending simulation is $20 \mathrm{~N}$.

Figure 10 shows when the Kapton substrate has a thickness between 0.01 and $0.048 \mathrm{~mm}$, as the substrate thickness increases, the stresses decrease. When the substrate thickness is higher than $0.052 \mathrm{~mm}$, as the substrate thickness increases, the stresses increase. A Kapton thickness in the range of $0.048-0.052 \mathrm{~mm}$ shows the lowest stress performance. When a fixed external stress is applied, the smaller the value of stress detected in the package the more reliable the package. So the range $0.048-0.052 \mathrm{~mm}$ thickness of the Kapton substrate is identified as the optimal thickness of substrate layer under shear and bending.

\subsection{Shear and bending load experimental to verify simulation}

To prove the simulation results, shear load and bending experiments have been undertaken under conditions which are as close as possible to the simulation conditions and parameters. The adhesive layer was applied by using a 


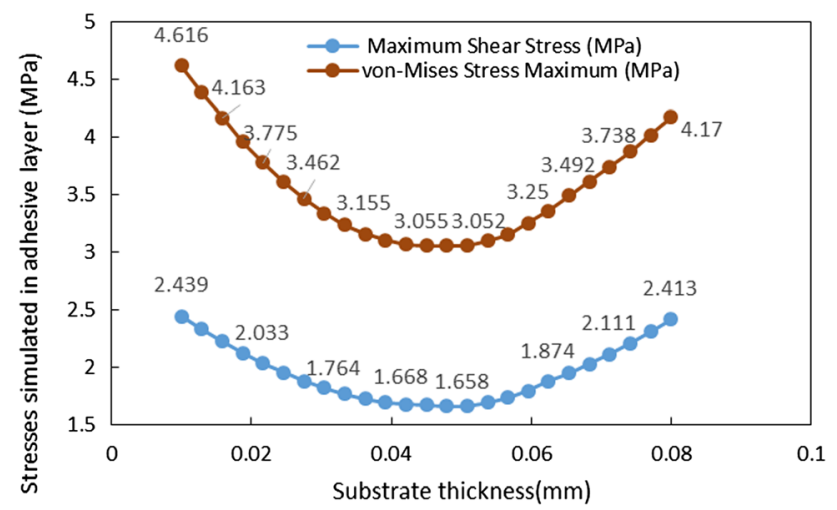

(a)

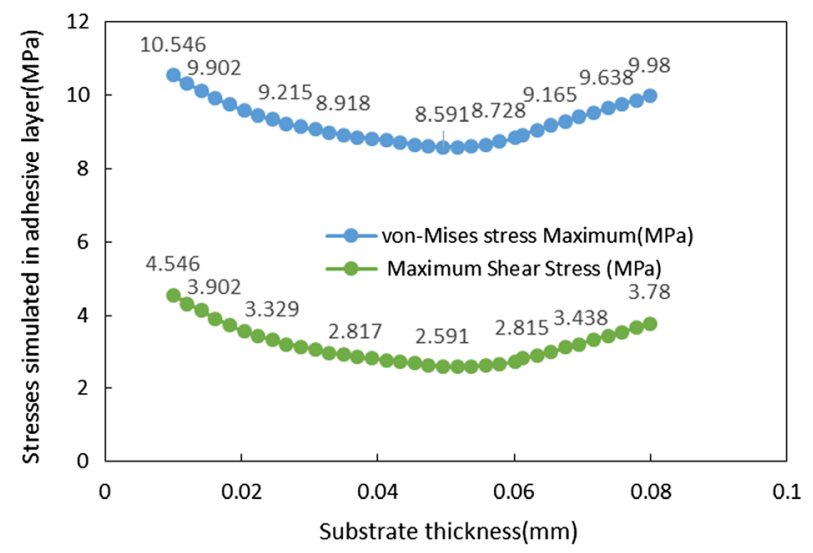

(b)

Fig. 10 Stresses simulation to determine optimal thickness of substrate layer, a shear load modelling to simulated maximum shear stress and von-Mises stress versus substrate thickness, $\mathbf{b}$ bending test modelling to simulated maximum shear stress and von-Mises stress versus substrate thickness

syringe and then a fixed weight was applied to the die to achieve the required adhesive thickness with different weights being used for the different adhesive thicknesses. Shear load and bending experiments are designed to detect the failure forces as a function of the thickness of the adhesive layer in the electronic package (Li 2018). The external force is applied at the point of failure of the adhesive. Multiple samples were used to plot Fig. 11 which indicate the external force required to cause electronic package failure as a function of adhesive thickness. The experiment is conducted with a $0.125 \mathrm{~mm}$ thick Kapton substrate and a $0.530 \mathrm{~mm}$ thick electronic die as in the simulations. Figure 11a shows shear load and bending simulation results for Loctite 4860 . The simulation results are used to compare with the experiment test results shown in Fig. 11b. The Y axis in Fig. 11a represents the maximum shear stress detected in the adhesive layer. The significance of this for the experiment is that for smaller maximum shear stress values detected in the simulation, a bigger force is experimentally required to cause a failure in

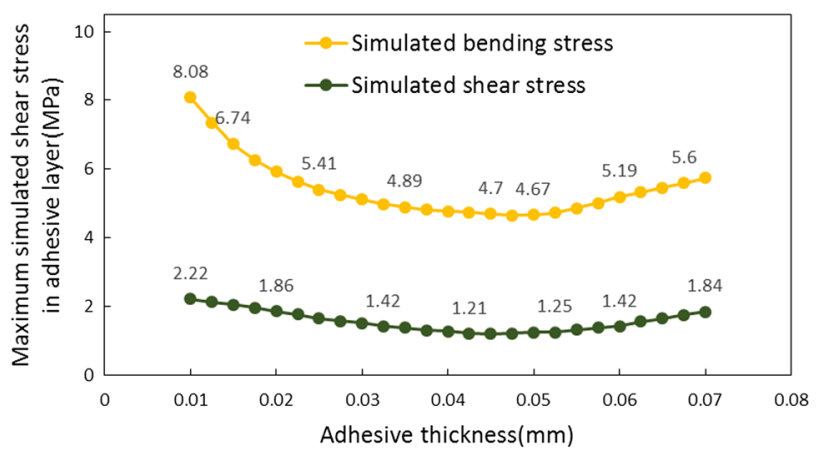

(a)

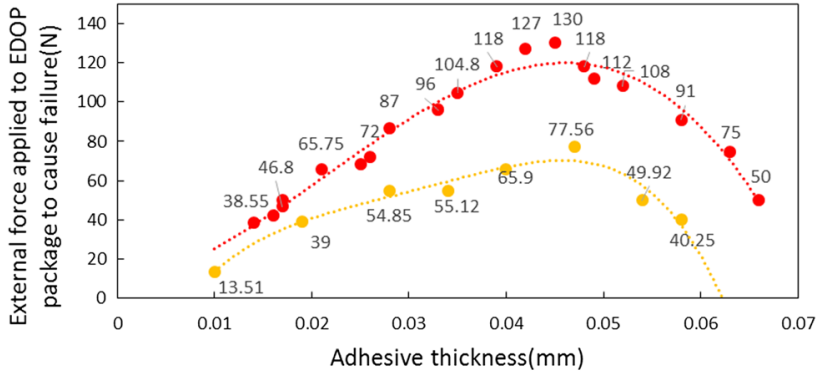

- Force applied (bending experiment) - Force applied (shear experiment)

(b)

Fig. 11 Experiment results to verify Loctite 4860 simulation results, a maximum shear stress detected in bending and shear load simulation, b maximum shear stress detected in bending and shear load experiment

the electronic package. In shear load simulation in the thickness range between 0.042 and $0.47 \mathrm{~mm}$ the minimum stress is detected. The shear experimental test results are shown in Fig. 11b, in the thickness range between 0.043 and $0.048 \mathrm{~mm}$, the maximum external force is needed to break the electronic package. This indicates that the optimal adhesive thickness of the Loctite 4860 layer in shear load test is in the range $0.042-0.048 \mathrm{~mm}$. In the bending test the optimal thickness is between 0.045 and $0.05 \mathrm{~mm}$.

Comparing the shear load simulation and experimental test results in the adhesive thickness of $0.01-0.042 \mathrm{~mm}$, as the thickness increases the shear stress in the simulation decreased while the external force detected in the experiment increases. This comparison proves the result of the smaller shear stress in simulation as a bigger force is experimentally required to cause a failure in the electronic package. The comparison between simulation and experiment for Loctite 4902 is shown in Fig. 12, the optimum adhesive thickness in simulation and experiment are between $0.04-0.045 \mathrm{~mm}$ and $0.042-0.045 \mathrm{~mm}$ respectively. The optimal thickness in both simulation and experimental results closely correlate. The small error value between simulation and experiment is because of the tolerance of the measured adhesive thickness. 


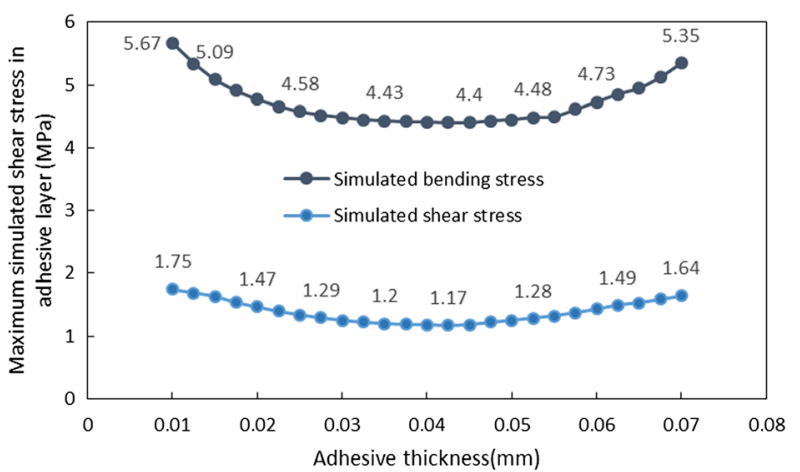

(a)

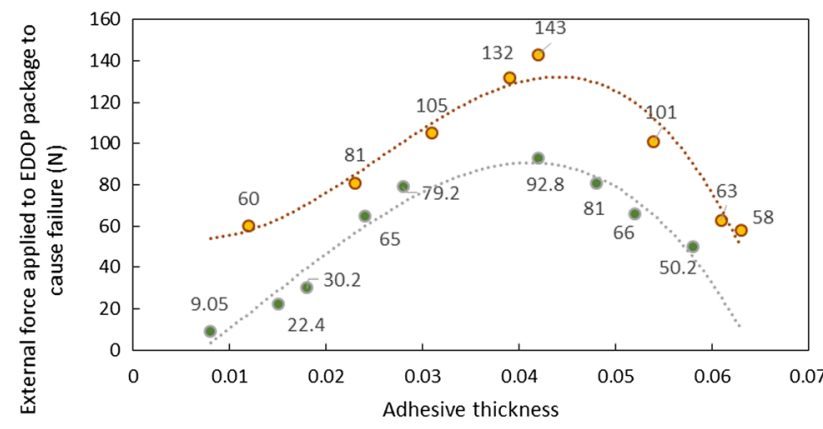

- Force applied (bending experiment) O Force applied (shear experiment)

(b)

Fig. 12 Experiment results to verify Loctite 4902 simulation results, a maximum shear stress detected in bending and shear load simulation, b maximum shear stress detected in bending and shear load experiment

\section{Simulation for electronic package with top encapsulation}

To provide additional mechanical protection for the electronic die, a top encapsulation layer is proposed for the previous package model (as shown in Fig. 1). Figure 13 shows the packaging method for encapsulating the die between two plastic films. The bending simulation was undertaken to determine the optimum thickness of the top adhesive layer.

Following the previous results, in this section the thickness of the bottom adhesive layer (Loctite 4902) is set to the optimal thickness of $0.045 \mathrm{~mm}$, the top and bottom plastic substrate used are Kapton with the optimal

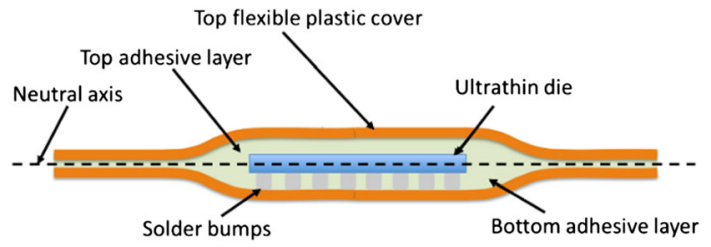

Fig. 13 Electronic package with top encapsulated flexible plastic to show the neutral axis thickness of $0.05 \mathrm{~mm}$, a $0.025 \mathrm{~mm}$ thick electronic die is between the Kapton layers and a constant force of $30 \mathrm{~N}$ was applied at the center of the top Kapton layer during the bending simulations. Layer thicknesses in the range of 0.01-0.07 $\mathrm{mm}$ for the top adhesive have been simulated.

Figure 14a shows the relationship between the thickness of the top adhesive and the Maximum von-Mises stress. When the thickness of the top adhesive layer is between 0.01 and $0.042 \mathrm{~mm}$, the maximum von-Mises stress decreases as the thickness of the adhesive increases. In thickness range of $0.048 \mathrm{~mm}$ and $0.065 \mathrm{~mm}$, the maximum von-Mises stress increases as the thickness of the adhesive increases. This simulation indicates that $0.042-0.048 \mathrm{~mm}$ of top adhesive layer gives the optimal von-Mises stress performance. The relationship between the thickness of the top layer adhesive and the maximum shear stress has also been simulated as shown in Fig. 14b. When the thickness of top adhesive is between $0.01 \mathrm{~mm}$ and $0.042 \mathrm{~mm}$, the shear stress decreased as the adhesive thickness increased. In the $0.048-0.065 \mathrm{~mm}$ adhesive thickness range, the shear stresses increased with increasing adhesive thickness.

The simulation results shown in Fig. 14 indicate that a $0.042-0.048 \mathrm{~mm}$ thick top adhesive layer will yield the

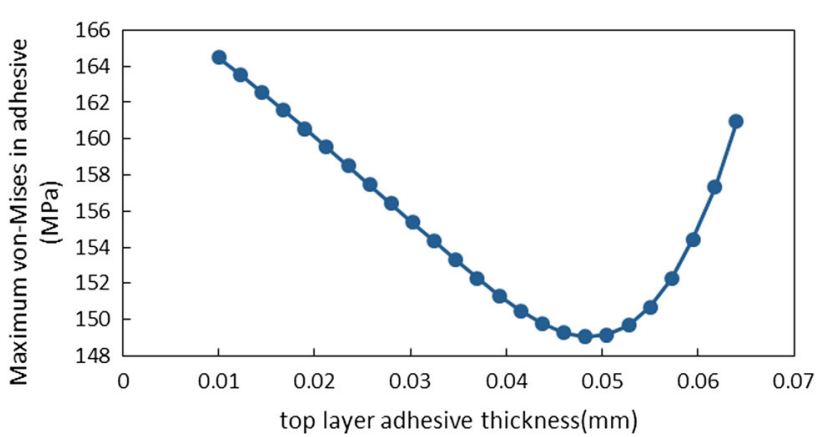

(a)

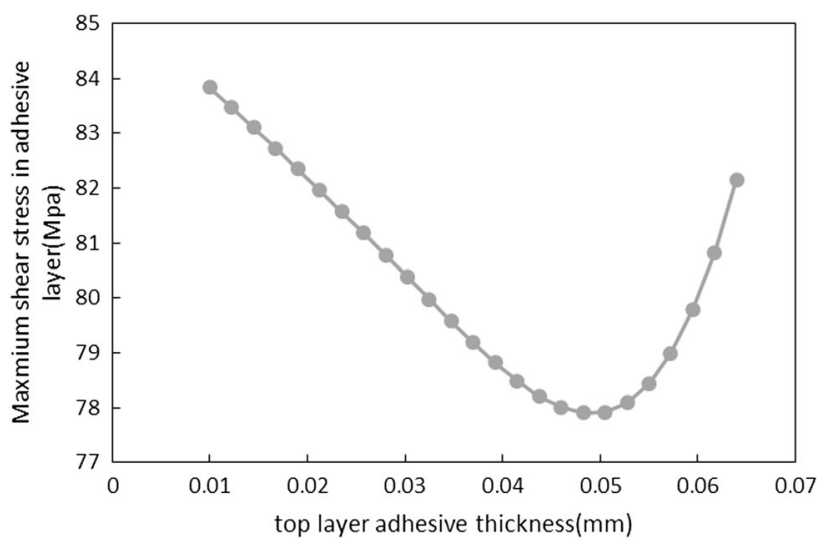

(b)

Fig. 14 Simulation of top layer adhesive thickness versus a maximum von-Mises stress and $\mathbf{b}$ maximum shear stress in bending test 
optimal maximum shear stress and von-Mises stress respectively.

\section{Simulation for neutral axis of electronic package}

To protect the electronic die in the proposed electronic package, the electronic die needs to be located close to the neutral axis of the complete electronic package to minimize stresses. The electronic package with top flexible plastic encapsulation (as shown in Fig. 13) is used to do the bending simulation to identify the neutral axis of the overall electronic package structure. The stress applied in the bending simulation is $20 \mathrm{~N}$ while the top and bottom plastic are $0.050 \mathrm{~mm}$ thick Kapton. The top and bottom adhesive layers are $0.045 \mathrm{~mm}$ thick and the electronic die is $0.025 \mathrm{~mm}$ thick; the adhesive used in this simulation is Loctite 4902. The simulation steps to determine the position of the neutral axis are: (a) simulate the stress distribution within the electronic package using the bending test model to determine the neutral axis region within the electronic package but cannot determine the exact location of the neutral axis, (b) simulate the stress distribution along a single line within the electronic package to detect the distance between the neutral axis and the top Kapton layer to determine the exact location of the neutral axis, this line starts from the centre of the top Kapton layer and ends in the centre of the bottom Kapton layer. Figure 15 shows the stress distribution on the electronic package, the green area shows the stress range of -5.91 to $20.956 \mathrm{MPa}$ which is the region of neutral axis.

Figure 16a and $\mathrm{b}$ shows the stress distribution in the centre line of the electronic package. Figure 16a shows the overview of where the centre line is located in the electronic package and the stress in the centre line. This figure shows that the maximum compressive stress above the neutral axis is $124.97 \mathrm{MPa}$ and the maximum tensile stress below the neutral axis is $127.3 \mathrm{MPa}$.

The $\mathrm{X}$ axis of Fig. $16 \mathrm{~b}$ is the distance between the top and bottom Kapton layers, this figure shows that the

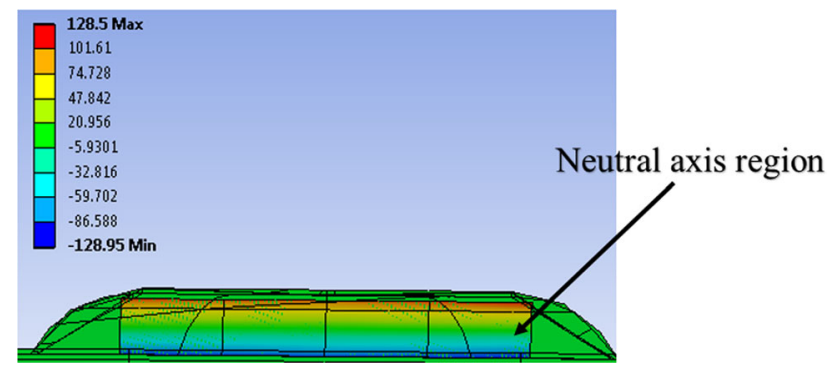

Fig. 15 Stress (unit: MPa) distribution in electronic package; green area in middle of the stack package shows the neutral axis region

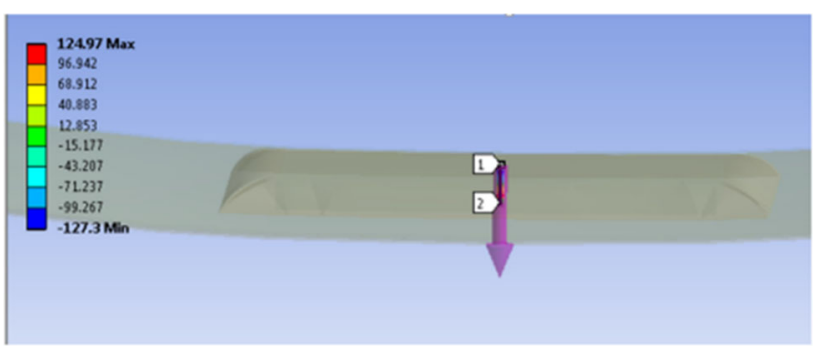

(a)

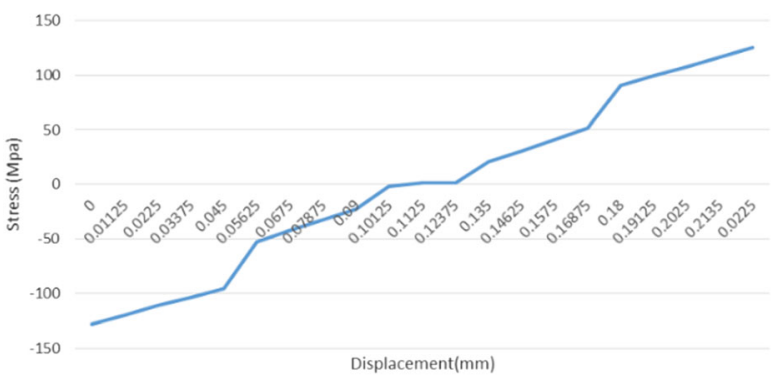

(b)

Fig. 16 a Stress (unit: MPa) distribution of centre line, $\mathbf{b}$ distance and stress distribution in between the top to bottom Kapton layers of the electronic package

distance between the top Kapton and neutral axis is $0.1075 \mathrm{~mm}$. A non-linear change in the stress is observed at the distances: $0.045 \mathrm{~mm}$ and $0.056 \mathrm{~mm}$. The reason for this non-linear change is because these positions are the transition points between the top substrate and top adhesive layer, the large difference of Young's modulus between adhesive and substrate produces these changes.

The same non-linear changes happened at distances of $0.09-0.106 \mathrm{~mm}, 0.114-0.130 \mathrm{~mm}$ and $0.162-0.178 \mathrm{~mm}$, which are the transition points between each consecutive layers of top adhesive and die layer, die and bottom adhesive layer, bottom adhesive and bottom substrate layer respectively. The stresses between 0.095 and $0.1075 \mathrm{~mm}$ are all small negative values $(-0.65 \mathrm{MPa})$ while the stresses between 0.1075 and $0.12 \mathrm{~mm}$ are all small positive values $(+0.65 \mathrm{MPa})$. The stress is zero at the distance of $0.1075 \mathrm{~mm}$ and this means that the distance between the neutral axis and top adhesive Kapton is $0.1075 \mathrm{~mm}$ which is half of this electronic package. The location of the neutral axis at the center of the electronic package indicated that if the material and thickness of the top and bottom Kapton layers are the same, and the material and thickness of the top and bottom adhesive layers are equally the same, then the neutral axis will located to the center of the electronic die. 


\section{Conclusions}

In this paper a novel FEA modelling method has been introduced to determine the optimal material and thickness for under-fill adhesive and substrate layer in a proposed new electronic package. The experimental results have been undertaken to confirm the simulation results with good correlation. The $0.045-0.052 \mathrm{~mm}$ thick Kapton substrate, Loctite 4902 adhesive, and $0.042-0.045 \mathrm{~mm}$ thick bottom adhesive layer and $0.042-0.048 \mathrm{~mm}$ thick of top adhesive layer were identified as the optimum materials and thickness. The neutral axis simulation for the encapsulated electronic component in this paper indicated that, the same material and thickness of the top and bottom Kapton and adhesive layer used to create the electronic package described in this paper (as shown in Fig. 13) allows the electronic die to be located in the neutral axis of the overall electronic package to minimize the stresses in the electronic package and improve reliability. The next step in this work is to devise a fabrication method for this proposed new encapsulation process.

Acknowledgements This work was supported by the Engineering and Physical Sciences Research Council through the project "Novel Manufacturing Methods for Functional Electronic Textiles" (EP/ M015149/1). Data published in this paper is available from the University of Southampton repository at https://doi.org/10.5258/ soton/d0141.

Open Access This article is licensed under a Creative Commons Attribution 4.0 International License, which permits use, sharing, adaptation, distribution and reproduction in any medium or format, as long as you give appropriate credit to the original author(s) and the source, provide a link to the Creative Commons licence, and indicate if changes were made. The images or other third party material in this article are included in the article's Creative Commons licence, unless indicated otherwise in a credit line to the material. If material is not included in the article's Creative Commons licence and your intended use is not permitted by statutory regulation or exceeds the permitted use, you will need to obtain permission directly from the copyright holder. To view a copy of this licence, visit http://creativecommons. org/licenses/by/4.0/.

\section{References}

Boedeker Plastics, Inc. (2019) PEEK (PolyEtherEtherKetone) specifications. http://www.boedeker.com/peek_p.htm?utm_source= google\&utm_medium $=$ cpc\&utm_campaign=PEEK $\% 20 \%$ 20International\&utm_content=peek $\% 20$ sheet\&utm_term $=\%$ 2Bpeek $\% 20 \% 2 \mathrm{Bsheet} \& \mathrm{gclid}=\mathrm{CO}$ ks6CM3tMCFaK37QodSXsP8Q
Bonderover E, Wagner S (2004) A woven inverter circuit for e-textile applications. IEEE Electron Device Lett 25(5):295-297

Castano LM, Flatau AB (2014) Smart fabric sensors and e-textile technologies: a review. Smart Mater Struct 23(5):053001

Chan YC, Alam MO, Hung KC, Lu H, Bailey C (2004) Effect of underfill entrapment on the reliability of flip-chip solder joint. J Electron Packag 126(4):541

DUPONT $^{\mathrm{TM}}$ KAPTON $^{\circledR}$ HN polyimide film (2019) http://www. dupont.com/content/dam/dupont/products-and-services/mem branes-and-films/polyimde-films/documents/DEC-Kapton-HNdatasheet.pdf

Henkel (2019) Search datasheet for Loctite 4902, 4860 and 480. www.na.henkel-adhesives.com/product-search-1554.htm. Accessed 23 Mar 2019

Kallmayer C et al (2003) New assembly technologies for textile transponder systems. In: Electronic components and technology conference. IEEE; 1999

Katragadda RB, Xu Y (2008) A novel intelligent textile technology based on silicon flexible skins. Sens Actuators A 143(1):169-174

Li M (2017a) Stress analysis and optimization of a flip chip on flex electronic packaging method for functional electronic textiles. IEEE Trans Compon Packag Manuf Technol 8(2):186-194

Li M et al (2017b) Stress analysis of flexible packaging for the integration of electronic components within woven textiles. In: Electronic components and technology conference (ECTC), 2017 IEEE 67th. 2017. IEEE

Li M et al (2018) The thickness and material optimization of flexible electronic packaging for functional electronic textile. In: 2018 symposium on design, test, integration \& packaging of MEMS and MOEMS (DTIP). 2018. IEEE

Loh KI, Chang S, Ibe ES (2013) Underfill encapsulants and edgebond adhesive for enhanceing of board level reliability. In: SMTA international conference proceedings. 2013, p 978-0-9888873-05 (C) 2013

Meoli D, May-Plumlee T (2002) Interactive electronic textile development: a review of technologies. J Text Appar Technol Manag 2(2):1-12

Mylay (2019) Polyester film. http://dupontteijinfilms.com/wp-con tent/uploads/2017/01/Mylar_Electrical_Properties.pdf

Nysaether JB, Lai ZH, Liu JH (2000) Thermal cycling lifetime of flip chip on board circuits with solder bumps and isotropically conductive adhesive joints. IEEE Trans Adv Packag 23(4):743-749

Paul G et al (2014) An investigation into the durability of screenprinted conductive tracks on textiles. Meas Sci Technol 25(2):025006

Rajoo R et al (2010) Embedding of 15 um thin chip and passives in thin flexible substrate. In: 2010 12th electronics packaging technology conference. 2010. IEEE

USA, Department of Defense (1996) Test method standard microcircuits. MIL-STD-883E, December 1996

Wan JW, Zhang WJ, Bergstrom DJ (2007) Recent advances in modeling the underfill process in flip-chip packaging. Microelectron J 38(1):67-75

Publisher's Note Springer Nature remains neutral with regard to jurisdictional claims in published maps and institutional affiliations. 